\title{
Design and development of solar power generating apparels
}

\begin{abstract}
In this research a wearable, portable solar back pack was designed and manufactured for charging the electronic devices such as mobile phone, iPod, mp3 players and laptop. A solar panel was used to convert the solar energy into electrical energy. The solar circuit consist of solar panel; composed of four solar cells (two of which attached in series \& remaining two attached in parallel), two ICs for controlling the voltage and rechargeable batteries for charging the devices in the absence of sunlight. The flexible micro solar panel was attached at the back of the back pack using sticky material and sewing technology. The wires and other accessories were attached inside the back pack, the batteries and charging pins were placed inside the pockets of Back pack. The designed apparel commodity not only serves the purpose of wearing but also charges the electronic devices up to $+24 \mathrm{~V}$. It is cheap, easy to detach, rechargeable with electric current and gives comfort to wearer.
\end{abstract}

Keywords: e-textiles, charging, apparel, solar cells, fossil fuels, environmental pollution, electricity, solar energy, silicon solar cells, solar radiation, garden light, geographical area, smart textile, tommy Hilfiger, shoulder strap
Volume I Issue 4 - 2017

\author{
Jemal Assres, Gebrehiwot Asfaha, Selemawit \\ Melaku
}

MF Tech Student, Bahir Dar University, Ethiopia

Correspondence: Jemal Assres, MF Tech Student, Ethiopian Institute of Textile And Fashion Technology, Bahir Dar University, Ethiopia,Tel 251941619113,Email jemytexas@gmail.com

Received: November 16, 2016 | Published: April 12, 2017

\section{Introduction}

Extensive use of natural and renewable energy sources is needed to minimize the burden of fossil fuels. Burning of high levels of fossil fuels induce climate change, air and environmental pollution. ${ }^{1}$ Moreover, reason for switching from fossil fuels to renewable sources is their huge consumption and rapid reduction. A variety of renewable energy sources are readily available such as sun, wind, tides, and geothermal activity. An initial cost and maintenance cost of renewable energy is high but has no fluctuation in prices when in use as compared to the prices of electricity and gas. It is because renewable energies are fully dependent on natural energy sources, hence, eliminating the dependence on fossil fuels. In third world countries such as in Ethiopia, approximately 90 percent of electricity originates from polluting sources of energy such as coal. Coal-fired power plants are responsible for pollution that increases asthma attacks and worsens environmental problems such as acid rain, haze, smog, and other air and water pollution.

Solar energy is the most promising of the renewable energy sources in view of its apparent limitless potential. In this connection solar cells are used in which the solar radiation is directly converted into electricity. The most common method of doing this is through the use of silicon solar cells. ${ }^{2}$ Sunlight is composed of photons, when photons strike a PV cell; they may be either reflected or absorbed or may pass right through. ${ }^{3}$

Only the absorbed photons generate electricity due to the transference of an electron in an atom of the cell (which is actually a semi-conductor). Different solar products have been launched such as solar chargers for cell phones and laptops and solar power for solar signals, emergency road signs, emergency call boxes, parking lights and garden lights. However, solar cell has few limitations such as its efficiency is decreased near the poles of earth, in cloudy weather and it is expensive. ${ }^{4}$
A term peak sun hours is used to smooth out the variations in daily average sun hours in different parts of the world. When planning a system your geographical area is rated in average peak hours per day based on yearly sun data.

Furthermore, research has been extended towards E-textiles. An integration of photovoltaic thin film cells into wearable such as backpack backpacks and pocket gave new concept of fashion and smart textile. ${ }^{5}$ These solar cells are graphically strong and need to be more visually integrated into the Apparel. Different solar backpacks have been introduced in Japan and other countries. These backpacks were capable of charging at low voltage such as cell phones only. Solar bags for charging laptops, cell phone and iPod were also introduced. Solar caps were also introduced and commercialized too. ${ }^{6}$ In addition, solar panels were attached in dresses such as bathing suits for charging cell phones and other devices with USB port.

Hence, it has been observed much work has been carried out on replacing the conventional energy system with the solar energy and use of solar energy in Apparels.

Researcher from Norwegian Metropolitan University has been working on power generating purse and the work is successful Figure 1. The purse is able to charge small smart phones and other LED batteries. $^{7}$

The world renowned fashion retailer brand Tommy Hilfiger has also designed and developed a solar power generating clothing's in 2014 Figure 2.

Paulin van dongen is a researcher and designer working to bring new technologies, like solar powered clothing's in to fashion, ${ }^{8,9}$ some of her works Figure 3.

There are also some other works in the field that have done a similar work in solar power harvesting apparels some of them are shown in Figure 4. 


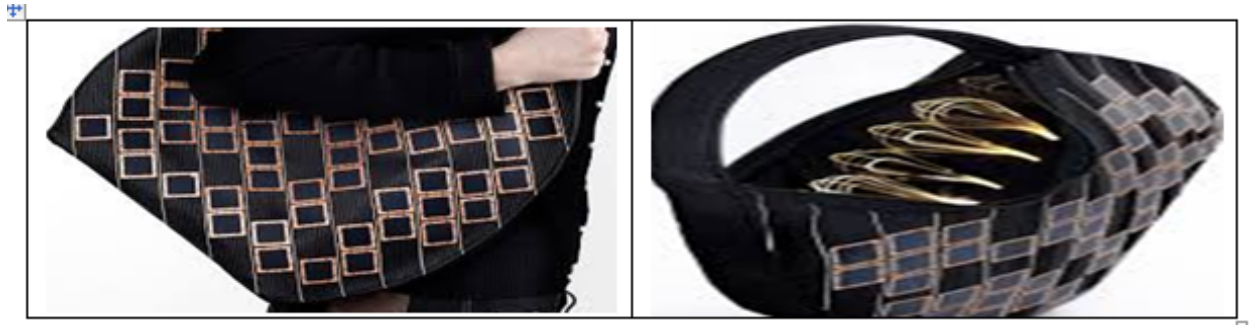

Figure I solar purse from Norwegian metropolitan university.

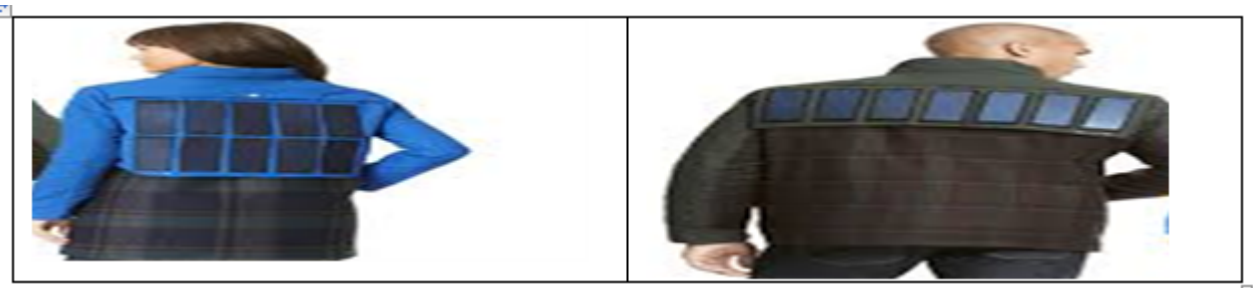

Figure 2 solar Backpack from Tommy Hilfiger.

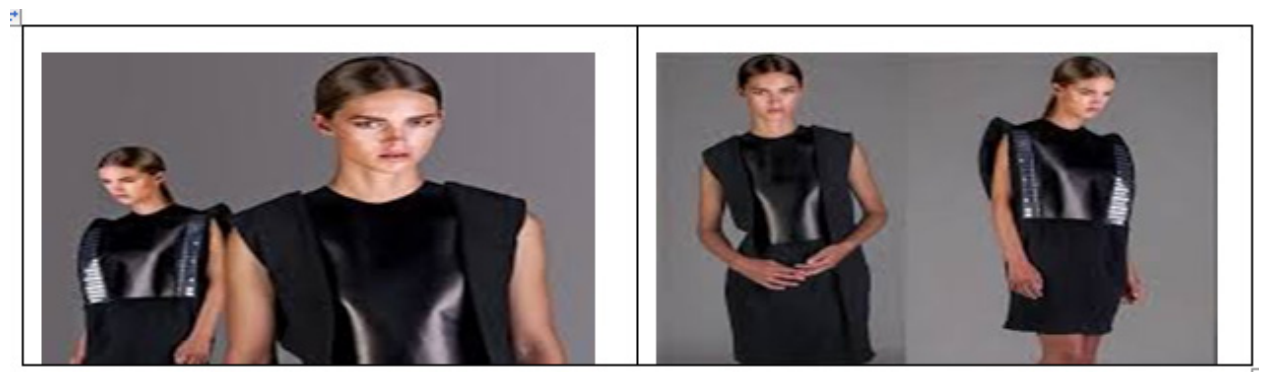

Figure 3 solar clothing's from Paulin van dongen.

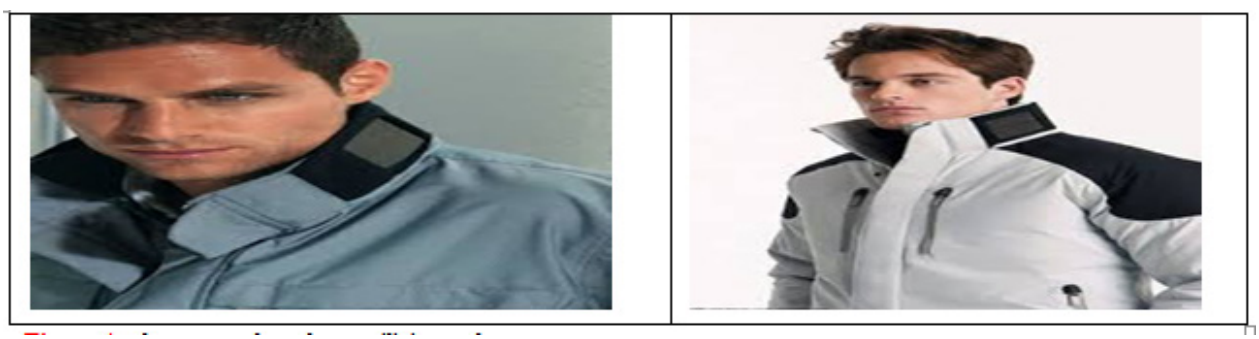

Figure 4 other apparel products utilizing solar power.

Therefore, in this research flexible and portable charging Apparel using solar energy system was designed. The Apparels can charge mobile phones, iPod, laptop and other devices that work up to +24 V. The design Apparel is cheap, portable, washable, comfortable and safe (no risk of electric shocks). The fitting of solar panel was done in such a way that optimum amount of heat via sunlight can pass through the panel and generate maximum energy.

However, the solar circuit can be attached in a variety of styles in the Apparel such as on back flap of the bag and pockets on shoulder strap.

The designed backpack has flexibility; it can be used for windy and harsh weather condition because of glass sheet coated on solar panel. For making backpack more flexible, small wafer solar cell can be used but this type of Apparel requires clean environment and weather.

\section{Design methodology}

\section{Research approach}

The research approaches that have been used in this research work are listed below: a. Material Preparation.

b. Research planning.

c. Design of apparel and panel arrangement.

d. Scientific analysis.

e. Development \& Publication of results.

The design of the selected apparel to make solar powered apparel is shown in Figure 5.

The reason why I have selected a back bag for the solar poser harvesting is that it is placed at the most exposed part of the human body to sun light exposure and other factors like the nature of the micro solar panels and the daily commodity that we all have it is being back bag Figure 6 .

Main components of solar panels are:

i. Panel: used to charger the battery

ii. Battery: provide DC voltage to the inverter 
iii. Inverter: converts $\mathrm{DC}$ voltage to $\mathrm{AC}$ voltage

iv. Charger controller: insures proper charging of the battery

v. Solar powers can be wired in series or parallel to increase voltage or amperage respectively.

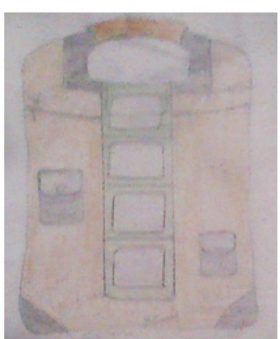

Figure $\mathbf{5}$ proposed solar powered apparel.

Series wiring: connecting the positive terminal of one panel to the negative terminal of another. The resulting outer positive and negative terminals will produce voltage the sum of the two panels but the amperage stays the same as one panel.

Parallel wiring refers to connecting positive terminals to the positive terminals and negative to negative terminals: The result is that voltage stays the same as one panel but the amperage becomes the sum of the number of panels.

Series/parallel wiring: doing both of the above: It increases volts and amps to achieve the desired voltage as in $24 \mathrm{~V}$ or $48 \mathrm{v}$ system.

For the current research I have used the third type of wiring solar panels which is Series/parallel wiring to use the advantage of increment of both amperage and voltage in Figure 7.

For designing the solar backpack; solar cell, ICs, rechargeable batteries and ready-made backpacks were used. It senses the sunlight and generates the DC voltage. Two ICs were used for charging the mobile, iPod, mp3 player and laptop and work as a charge controller. There were four rechargeable batteries (each of $4 \mathrm{~V}$ and $1.2 \mathrm{~A}$ ) connected to store the electric charges and can be used to charge the devices in the absence of sunlight. A reverse diode was also attached for one way passage of current. The solar panel of $3 * 5$ inches was sealed using glass sheet coating. For attaching the solar panel along with 'other accessories (circuit as shows in Figure 7), a hole of $2 * 1.5$ inches was cut for solar panel and $8.5 * 8.5$ inches was cut for wires inside the backpack. Through the hole, wires and ports were passed into the first layer of bag. Whereas, panel was attached at the back of the backpack using sticky gum and sewing techniques.

If the solar panel is attached near to the neck, it irritates the wearer. Further, if it is attached below this level, it would affect the appearance of the garment and also exposure to sunlight would be affected the life of circuit. Other accessories of solar panel such as wires were attached using the small pins. An inside battery holder as shown in Figure 8 was used to hide and cover the circuit and wires. The rechargeable power bank was used to connect the charger pins; that were placed at inside of the back pack Figure 2 .

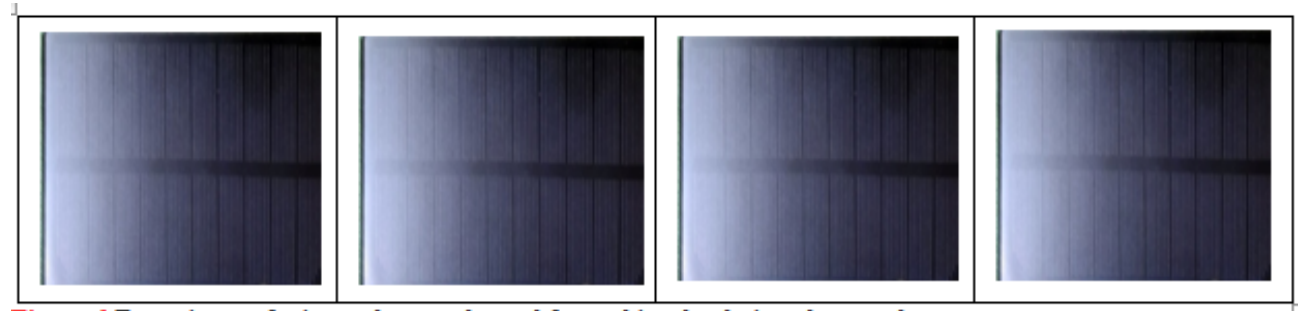

Figure 6 Four pieces of micrō solar panels ūsed for making the desígned appärel.

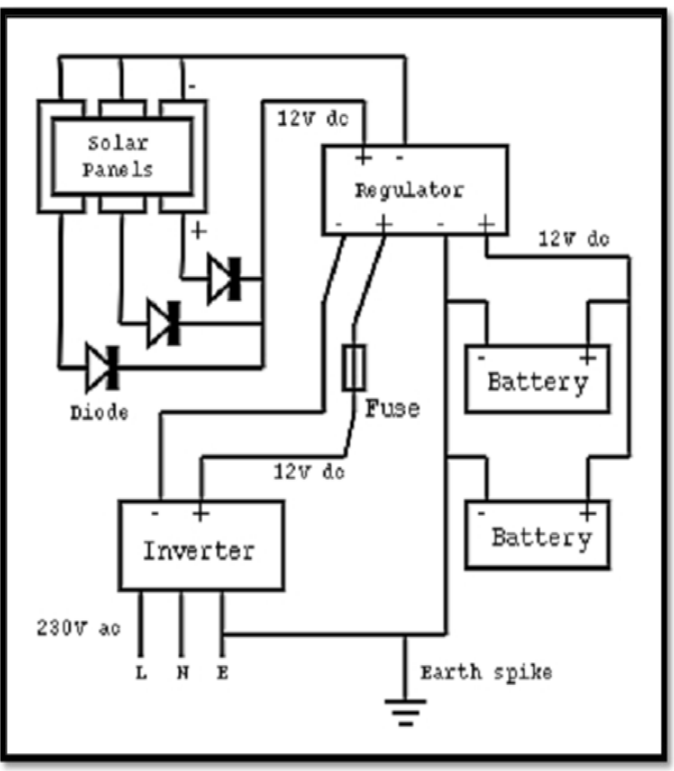

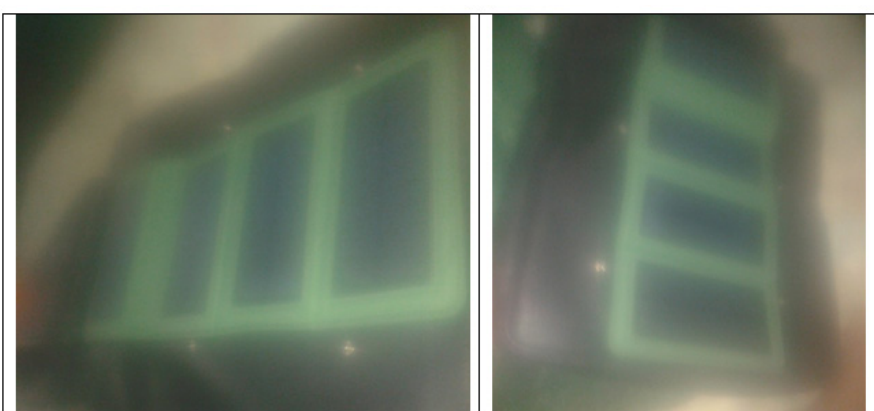

Figure 8 developed solar power generating bag.

\section{Acknowledgements}

None.

\section{Conflict of interest}

Author declares there is no conflict of interest in publishing the article.

Figure 7 Solar circuit. 


\section{References}

1. Natural and Renewable Energy. 2016.

2. Sambo AS. Renewable energy for rural development: the Nigerian perspective. ISESCO Science and Technology Vision. 2005;1:12-22.

3. How A Photo voltaic Cell Works. The NEED Project, Manassa, USA; 2011. p. 43.

4. How Solar Power Works? 2016.
5. Hynek JS, Campbell JR, Bryden KM. Application of digital textile printing technology to integrate Photovoltaic thin film cells into wearables. Wearable interactions. 2010.

6. Schaeffer J. Solar hot fan, the real goods solar living. 12th ed. Hopland, California; 2005. p. 252.

7. The solar handbag. 2017.

8. Solar Bikini, The swimsuit that can make you stay connected, solarcel.

9. swimsuit-make-stay-connected.html 